\title{
To Meat or Not To Meat?
}

\section{An Analysis of On-line Vegetarian Persuasive Rhetoric}

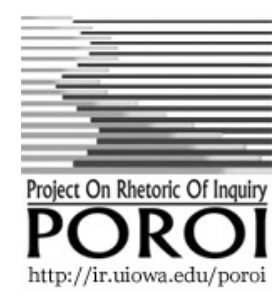

\section{Beth Jorgensen}

Saginaw Valley State University

Saginaw, $M I$

Poroi 11,1 (May 2015)

Keywords: Vegetarianism, veganism, Frances Moore Lappé, Peter Singer, Ancel Keys, food system, heart disease, animal cruelty

Two chickens, their feathers bedraggled, huddle together in apparent fear. The actor Alec Baldwin narrates, "What you are about to see is beyond your worst nightmares." A startling montage begins-a poultry worker herding birds against a wall as an injured hen struggles to stand, pigs in crates unable to roll over, rows of chickens on a conveyer line. So begins Meet Your Meat, produced by People for the Ethical Treatment of Animals (PETA), one of many organizations promoting an animal-free diet and/or lifestyle (Friedrich and Akin, 2002).

In 1971, only one percent of the U.S. population considered themselves to be vegetarian (Euromonitor International, 2011). By 2000, a Vegetarian Resource Group poll indicated that 2.5 percent of respondents reported diets free of meat, poultry, or fish (The Vegetarian). The upward trend continues. Harris Interactive reported in 2008 that ten percent of adults lean towards vegetarianism, 3.2 percent identified as wholly vegetarian, another .5 percent as vegan (vegans abstain from all animal products including eggs, dairy, and sometimes even honey). In 2012 and 2013, respectively, Gallup reported an increase to five percent vegetarian, two percent vegan (Newport, 2012). Public Policy Polling reported six percent vegetarian and seven percent vegan, reaching a high of thirteen percent of U.S. citizens polled (Jensen, 2013).

The 1970s were arguably a pivotal decade for the development of this trend, as a number of seminal works were published that encouraged reduced consumption of animal products, including Frances Moore Lappé's Diet for a Small Planet (1971), the first bestseller to take a hard look at the food system; Peter Singer's 
Animal Liberation: Towards an End to Man's Inhumanity to Animals (1975), now considered the seminal text of the animal rights movement; and Ancel Keys et al.'s Seven Countries: A Multivariate Study of Death and Coronary Heart Disease (1980), which advanced the position that countries whose native diets are lower in animal fats have lower incidence of coronary disease and led to widespread recommendations that consumers reduce dietary animal fat.

\section{LAPPÉ}

While historically, vegetarianism has largely been practiced for spiritual and/or religious reasons associated with animal cruelty, Frances Moore Lappé extended ethical vegetarianism into the realms of ecology and social justice. Her premises are that consumption of meat wastes protein in a world of scarcity and that meat production has dire environmental consequences. In Diet, Lappé's rhetorical strategy is to establish the ethical basis for a meatless diet while reinforcing the reader's motivation with a turn toward personal health. For example, she notes that soil depletion has lowered the protein content of wheat and she opposes pesticides and herbicides on the premise that they are harmful to human health rather than that they are harmful to the biosphere (Lappé, 1971).

\section{SINGER}

Peter Singer operates from Joseph Priestley's $18^{\text {th }}$-century utilitarian position that ethical behavior can only be evaluated by "the greatest good for the greatest number." Counting non-human animals among the numbered, he finds the distinction between humans and other animals to be arbitrary, as chimpanzees are more human-like than fish, although both are labeled as "animals." In the face of arguments that rights should not be extended to less intelligent animals, Singer points out that rights are extended to humans who have severely limited mental capacity and that animals sometimes display intelligence comparable to that of young children. Singer does not condemn the consumption of meat outright, as he acknowledges that livestock may be raised and slaughtered humanely; rather, he condemns confinement animal feeding operations (CAFOs), arguing that because most meat stems from this industry, the most ethical path is to avoid eating meat. Singer concedes that a "conscientious omnivore," that is, a person who consumes humanely raised animal products, has taken an ethical position (Singer, 2009). 


\section{KEYS ET AL.}

In 1957, Ancel Keys and fifteen colleagues began field surveys in the U.S., Italy, Greece, Yugoslavia, the Netherlands, Finland, and Japan to examine the impact of diet, lifestyle, risk factors and rates of coronary heart disease and stroke among populations who differ in levels of dietary fat. Repeating the surveys at five- and ten-year intervals over forty-five years, they concluded that high blood cholesterol and consumption of saturated fats raise one's risk of atherosclerotic diseases (Keys et al., 1980). Based on these findings, recommendations for low-fat diets initially focused on populations suffering from heart disease. However, in 1970, these guidelines were extended to pregnant women and children when the U.S. Department of Agriculture's Women Infants and Children (USDAWIC) program recommended that pregnant women and children over age two be limited to skim or nonfat milk, signaling the movement of low-fat diets into the mainstream (Watson, 2013).

\section{WHY MOTIVATION MATTERS}

Of particular interest is whether one or more of the above rationales, as represented and promoted by Lappé's, Singer's, and Keys' texts, motivate consumers to go meatless. On one hand, any singular motivation may neglect important elements of the others. For example, health aficionados may neglect environmental concerns while animal rights devotees may neglect health concerns. On the other hand, motivations for vegan/vegetarian diets may overlap; arguments that monocrop grain production harms the environment may mesh with arguments that grain-fed meat is high in fat and, therefore, unhealthy. Likewise, arguments that CAFOs are inhumane may mesh with those concerned with the environmental impacts of these operations or the use of antibiotics and hormones that cause detrimental human health effects. Thus, of greatest interest is the intersection of these concerns, particularly with regard to awareness and perceptions of the global food system. A number of concerns, both health-related and environmental, emerge when motivations for going meatless are not connected with an understanding of the global food system, as distinctions between the concerns about animal rights may trump environmental concerns or health concerns and vice versa.

For example, animal rights activists may not make nuanced distinctions among wildlife, livestock, and domestic pets. They may oppose hunting, although hunting for food may reduce one's environmental footprint by providing meat from outside the environmentally destructive CAFO system, as well by stabilizing 
populations of wildlife (deer for example) that may cause ecosystem destruction when not checked by natural predators. Additionally, many animal rights activists support "no-kill" shelters and help to maintain feral cat colonies despite evidence that cats are a leading killer of songbirds, that colonies of them disrupt natural ecosystems, and that pets consume scarce global food resources. Further, an animal rights emphasis may gloss over concerns about air and water pollution, as well as greenhouse gases, produced by CAFOs.

Meanwhile, an emphasis on personal health may stand in tension with environmental/food system concerns. For instance, many consumers choose organic due to fears about food safety, overlooking the environmental impact of food transportation, a significant concern, since much organic food marketed in the U.S. comes from as far away as China. Also, an individual may adopt a meatless diet for health reasons irrespective of ecological concerns. Dietary habits also tend to follow the latest trends; recent decades have seen a variety of diets come and go, e.g., Beverly Hills, Atkins, Scarsdale, Pritikin, and the Zone. Many feature a heavy emphasis on protein from meat, as in the currently popular Paleo diet that increases rather than decreases one's environmental footprint.

At bottom, connecting diet to a sustainable global food system must take into account a number of factors: environmental, economic, cultural, anthropological, humanitarian, and nutritional. As laid out in the United Nations' 1987 World Commission on Environment and Development report, sustainability requires that individual diets consider the needs of the global population, particularly the world's poor, and the limitations that proscribe the environment's ability to meet those needs now and in the future (Brundtland, 1987).

\section{CONSUMER PERCEPTIONS OF THE FOOD SYSTEM}

Surveys from the Center for Food Integrity indicate that most consumers have a vague sense that "big is bad" with regard to food production and processing, although most are not entirely clear about why (Center for Food Integrity, 2013). While most people believe that large-scale farming is more likely to cause environmental damage than small-scale, few see U.S. farming as an environmental concern, although more express concern about the environmental effect of other countries' farming (Bostrom, 2005). Aubrun et al. suggest that one reason for this lack of clarity may be "little-picture models" of the food system that "crowd out" the 
bigger picture, "distort" information provided by advocates and experts, and reduce the "food system" to individual issues such as shopping, cooking, and healthy eating, rather than systemic issues (Aubrun et al., 2005). Overall, Aubrun et al. find that most consumers are unfamiliar with, even perplexed, by key concepts. "Sustainability" means little except that soil becomes depleted over time or that farmers struggle to pass down farms to offspring. "Sustainability" as well as "diversity" often stand in "direct contradiction" to "normal attitudes toward progress," contradicting the assumption that modernization depends on standardization for efficiency. Agricultural subsidies and organic farming are likewise seen as a resistance to modernization, as consumers often perceive that family farms are part of an "idyllic Rural Utopia" unconnected with the real food system and that farmers' markets are "old fashioned, inefficient (inconvenient), [and] quaint." On this note, Bostrom concludes that U.S. consumers generally trust the nation's food system and see little need for government intervention (Bostrom, 2005).

Moreover, Aubrun et al. raise concern that more critical consumers merely opt out by buying organic or free-range foods rather than trying to reform the present system, raising concerns about the "Myth of Consumer Demand" that "obscure the ways in which consumer behavior is created, shaped and constrained by the Food System." Views of organic foods themselves are problematic, however, largely due to price point (Aubrun et al., 2005). When respondents to a study from the Leopold Center for Sustainable Agriculture were asked if they would support organic labeling, seventy-nine percent agreed only if cost did not increase. Carbon emission labeling fared more poorly, at forty-four percent, even if price remained the same. Twenty-five percent opposed such labeling under any circumstances (Pirog and Rasmussen, 2008). Bostrom shows stronger support, at eighty-six percent, although respondents were not surveyed with regard to consequent price increases (Bostrom, 2005).

Munkres finds that enthusiasts of organic food conflate the benefits of organic with those of local, assuming that local foods are less likely to be contaminated with herbicides and pesticides (Munkres, 2007). In the Leopold study, local wins out over organic; respondents indicate that knowing place of origin is more likely to increase consumer confidence than knowing that the food is organic (Pirog and Rasmussen, 2008). Similarly, only ten percent of Bostrom's respondents regularly buy organic and many seem to lack awareness as to what constitutes organic, given that 
only one in four express awareness of concerns about overuse of antibiotics and hormones in livestock (Bostrom, 2005).

Taken together, these studies indicate a "fuzzy" awareness of the global food system among U.S. consumers, although awareness of health concerns, particularly food safety, seems somewhat stronger. While not addressed by studies, livestock welfare seems to be of some concern, although consumers seem reluctant to pay more for either humane or eco-friendly food.

\section{METHODS USED IN THIS PAPER}

To get a sense of the online vegetarian/vegan community's motivations to go meatless, I first aggregated the frequency of stated positions from an About.com web site that solicits responses to the question "why are you vegetarian?" My criteria for selecting About.com were three-fold: 1 ) the site is removed from any context that may prompt respondents to favor a particular rationale or to recall a buried rationale; 2 ) it elicits a large number of spontaneous responses; 3) it emerged very near the top of the selections of unsponsored sites in response to my query "why vegetarian" through various browsers and search engines.

Next, I examined the frequency of talking points on web sites promoting a meatless diet. My criteria for selecting sites corresponded to the third criterion. As this study is concerned with persuasion and motivation, I excluded most recipe sites, as their primary purpose typically is community support rather than persuasion. Instead, I looked at sites that offer explicit lists of reasons for dropping meat from one's diet, including

- Vegetarian Times

- Vegetarian Guide

- Whybeavegetarian.net

- Vegetarian Victoria

- Happy Cow

- PETA

- The Whole Earth Vegetarian Cooking

- Vegecyber

I excluded news stories from the search results, choosing instead to focus on web sites promoting meatless living. I then took a thorough look at the full content of twelve websites that promote vegetarianism/veganism, selected according to the third criterion aforementioned. I compared their mottos and mission statements and then analyzed site content. I included the following websites, after eliminating strictly cooking and diet-support sites: 
- The Vegetarian Site

- VegNews

- ChooseVeg

- GoVeg

- Happy Cow

- VeggieGlobal

- Vegan Outreach

- North American Vegetarian Society

- The Vegetarian Resource Group

- TryVeg

- Veg Source

- The Vegan Society

I identified motivations for meatless living by invoking these as lenses: Lappé, food systems/environment; Singer, animal rights; Keys, health and nutrition. Keyword coding for food/systems, animal rights and health were relatively straightforward: animals, cruelty, planet, environment, ecology, health, weight, heart disease, diabetes, etc. Keyword coding for food system awareness was more challenging, as most keywords in isolation proved inadequate. I therefore looked for individual responses that included multiple keywords and phrases related to interrelated concepts, including environment, transportation, cropping practices, biodiversity, food system, global food policy, and food scarcity. I excluded isolated comments about livestock conditions, slaughter, and hunting, as these seemed to fall under animal rights, a single-lensed motivation which, as described earlier, sometimes glosses over environmental concerns such as manure and/or game management.

\section{RESULTS}

\section{Frequency of Talking Points}

About.com provides a lively chat resource for vegans and vegetarians to share reasons for adopting a meatless diet. At the time of my reporting, 843 respondents had weighed in. While some respondents provide multiple reasons, others state only one. Accordingly, the number of stated reasons exceeds the number of responders, at 1249 (Hackett, 2014). Animal rights dominates the chat, with 64 percent of respondents indicating that they became vegetarians to avoid cruelty. Notably, only 27 people offered a response that demonstrated awareness or concern for the food system beyond the perceived cruelty of CAFOs. Second is health at 46 percent. Environmental concerns ring in only at 12 percent. A variety of other reasons are given in very small numbers, including 
general ethics, faith, cost, taste, feeding the world, and being raised vegetarian.

Of the eight websites that offer explicit reasons for becoming vegetarian, Vegetarian Times serves primarily as a resource for individuals consuming a meatless diet. Nevertheless, it features an explanatory list of rationales: eight health-related, two related to food systems, and one concerning animal welfare. One reason, avoidance of herbicides and pesticides, addresses both health and environmental concerns. The site's statement, "Agricultural activities that cause pollution include confined animal facilities, plowing, pesticide spraying, irrigation, fertilizing and harvesting," indicates understanding of the global food system; the site's search engine produced two pages with dozens of links regarding animal welfare and environmental concerns. Nevertheless, their splash page contains no permanent references or links to either topic, presenting the site as a source for recipes and dietary informationwhich may indicate a savvy rhetorical strategy of focusing on personal needs rather than concerns that may be viewed as political and/or radical.

Whybevegetarian.net likewise serves as a starting place for access to information about vegetarianism. The feature article largely emphasizes health, although it lightly touches on the environment and animal cruelty while demonstrating a surface understanding of the food system, briefly addressing a variety of environmental impacts caused by animal protein production. Nevertheless, the inflated statement, "All vegetarians are animal lovers, so they ... believe that eating meat is murder," indicates a leaning toward animal rights.

Happy Cow's article on reasons to go meatless, "Compassion for the Animals," clearly reveals the site's ethical priorities. The feature devotes nearly twice as much space to animal cruelty as to ecological rationale, 769 words, plus a second-by-second counter of the number of animals slaughtered by the food industry. Their discussion of the environment demonstrates a reasonable understanding of the food system as they list an assortment of environmental harms stemming from meat production. Health gets short shrift, at 103 words.

As The Whole Earth Vegetarian Catalog is the online version of the Lumen Foods vegetarian/vegan food catalog, health dominates, with 28 health-related reasons to go meatless. Environment and animal rights are treated relatively equally, at five and six respectively. Various aspects of the food system are addressed (Caton, N.d.). 
The Vegetarian Guide offers health, animal rights, and environmental reasons for being a vegetarian, with emphasis on the environment. It takes a fairly in-depth look at the food system. No direct link exists in the menu for animal rights, although health links are included (Bluejay, N.d.).

Vegetarian Victoria, an Australian non-profit organization that promotes and supports meatless diets, offers two features, one promoting vegetarianism, in which health dominates over animal rights and the environment, the other promoting veganism, in which animal rights dominates. The vegetarianism feature indicates a fairly well developed sense of the food system ("Why Be").

Surprisingly, given their name and mission, PETA's piece on "Top 10 Reasons to Go Vegan in the New Year" prioritizes health over both animal rights and the environment in contrast to the bulk of their site - perhaps indicating an attempt to appeal to a broader audience (PETA, N.d.).

Vegecyber, an online site for ordering vegetarian food products, lists "10 Reasons to Be a Vegetarian," which are actually ten categories. The breakdown balances health with environmental and food system arguments, at 15 and 14, respectively. Five reasons cite animal rights (Vegetarian Food, N.d.).

\section{WEBSITE CONTENT}

Of 12 websites that promote vegetarianism/veganism, 9 include mottos and mission statements that promote animal welfare, 11 promote health, and seven promote environmental protection. Six use all three lenses.

While The Vegetarian Site promotes health, environment, and animal rights, the latter stands out as its primary motivator; the homepage emphasizes "animal abusers," animal testing, and nonfood vegan products (The Vegetarian Site, 2014). Their link to ethics and animals features five articles, while their diet and health links feature 13, the bulk addressing the safety or management of a meatless diet rather than persuading the audience to "go veg." The site features four articles on environmental concerns, one of which raises concerns about the use of blood and bone meal in organic farming and gardening for reasons of animal cruelty. The site does not provide a list of frequently asked questions (FAQ), but its editorial page features 14 commentaries, half of which address animal cruelty, and the other half an assortment of issues from agricultural subsidies to persuasive strategies for converting meat eaters. 
The motto "Eat. Think. Thrive." seems to suggest that VegNews is likely to feature the health benefits of vegetarianism or veganism. Upon a closer look, however, the site is decidedly vegan, emphasizing animal rights and the environment as rationales. Animal rights dominate the news page, and the environment pages tend to feature advice on green living rather than arguments for going meatless. While health and nutrition are featured, articles largely focus on how to be a healthy vegan rather than on why veganism is healthier than meat eating.

The splash page of ChooseVeg leaves the initial impression that it is largely a recipe site, although links take the reader to pages on animals, health, and the environment. The Animals page features anthropomorphized stories of animals, while their environment page offers statistical infographics. The health page focuses on obesity, diabetes, and heart disease. The page is a fairly balanced take among the three lenses, although prominent display of the Mercy for Animals logo indicates that animal cruelty is of highest priority.

Images of animals dominate the splash page of the GoVeg website, making clear their primary motivation, yet they also provide fairly extensive information as to why a vegan diet is healthier than a meat-based diet. The link to environment is a mere 586 words, compared to 2181 and 1590 for health and animals respectively. Nevertheless, the environment link looks at various aspects of the food system. Meanwhile, a "Resources" dropdown menu, which provides links for "Compassionate Living," "Know More and Do More," and "Youth," is entirely devoted to concerns about livestock welfare.

The restaurant guide Happy Cow provides a dropdown menu that includes links to health, animal rights, and the environment. The health link features a single paragraph on the benefits of a meatless diet and links to diet and nutrition resources, while the animal rights link provides a list of reasons to go vegetarian/vegan including environmental and humanitarian reasons, as well as links to related articles and documentaries. Animal welfare, health, and the environment are very closely associated on this site, demonstrating a latent understanding of the food system. A number of sites and blogs, including Groupon, referenced Happy Cow as "The Compassionate Eating Guide" as recently as 2010, whereas their slogan read "The Healthy Eating Guide," signaling a shift to a less ethically charged rhetorical strategy.

The VeggieGlobal website covers humanitarian issues as well as animal rights and the environment. Health benefits are not a 
priority, except as connected with environmental destruction or humanitarian crises, although it offers guidelines for eating vegan. Animals are at the core of its mission, as habitat destruction dominates its environmental links and they include a "lost-andfound animals" network (VeggieGlobal, N.d.). Moreover, their FAQ section promotes veganism rather than vegetarianism, largely due to concerns over animal welfare.

Vegan Outreach clearly states their purpose as "working to end cruelty to animals" (Vegan Outreach, n.d.). Yet they effectively connect animal cruelty to other problems with the global food system, including health and environmental concerns.

Nevertheless, they devote most of their persuasive content to CAFOs.

The banner of the North American Vegetarian Society site, "Advocating Healthy, Compassionate and Ecological Living," clearly ranks their priorities. Eleven articles appear on health and nutrition for non-meat eaters, only one of which strives to directly persuade the audience to adopt such a diet. Their FAQ offers 19 answers related to health, diet, and lifestyle. Meanwhile, six features concern animal rights and the FAQ addresses four questions concerning cruelty. Although only two articles address environmental concerns, both provide a solid look at the food system. The single environmental FAQ also addresses the food system as a whole.

The Vegetarian Resource Group likewise emphasizes health, featuring over 50 articles and FAQs on diet, the majority focusing on managing eating habits rather than persuading readers to adopt a meatless diet. Fifteen articles and FAQs are featured on the environment, with a strong focus on the food system. Although the site does not include a link to animal rights, the FAQ section indicates that most of the employees are vegetarians due to animal rights.

The TryVeg diet and recipe site evenly balances coverage of health, environment, and animal welfare, providing a concise summary of concerns about various aspects of the food system.

VegSource is an expansive site with hundreds of articles of interest to vegetarians/vegans, as well as readers concerned with animal welfare and the environment (VegSource, 2014). The site is notable for thorough coverage of the food system.

The Vegan Society's answer to "Why Go Vegan?" states that the diet is "healthier, greener, kinder to animals and our planet's future" (The Vegan Society, N.d.). However, their definition of 
veganism calls for eliminating "exploitation of, and cruelty to, animals for food, clothing, or any other purpose," advocating even the avoidance of honey. They likewise adviser consumers to avoid medications that contain animal products, medical charities that perform animal-testing, and entertainment that involves animals, such as zoos, aquariums, and horse-racing. While their "Why Go Vegan?" link gives a nod to environmental and global humanitarian concerns, the site decidedly focuses on animal welfare.

Overall, while most of these sites include environmental and health arguments, animal welfare either dominates or underlies the rhetoric aimed at persuading individuals to adopt a meatless dietcorresponding with Singer's ethics. Although a number of sites make weak associations between animal rights and the environment, other sites indicate that animal welfare often provides a first step to understanding the food system, thus indicating that Singer's position may provide a link to Lappé's. Meanwhile, discussions of health most often focus on how to eat a healthy diet while vegetarian or vegan, rather than why a meatless or animalfree diet may improve health; thus Keys' arguments seem to be nearly off the radar. Indeed, only $1.8-2.4 \%$ of respondents to the About.com site indicated that health-related reasons for going meatless were specifically due to concerns about dietary fat and cholesterol or coronary diseases, respectively.

Aside from the About.com site, all sites examined engage in the clear purpose of persuading their audiences to adopt a meatless diet. However, two concerns emerge in the methodologies of the reviewed surveys: sample sizes are often quite small and samples may not have sufficient control. I thus compared online data from an assortment of surveys to obtain a somewhat more neutral view. Available data to an extent confirm the trends noted above. For example, a 2008 Vegetarian Times survey of 5,050 Americans indicates that animal rights leads the list at 54 percent-although the lead is short, as overall health follows at 53 percent. Indeed, health seems to be a major motivator, as 39 percent mentioned "natural approaches to wellness," 31 percent cited food-safety concerns, 25 percent weight loss, and 24 percent weight maintenance. Environmental concerns did well in the survey, cited by 47 percent (Harris Interactive Polling, 2008). To a certain extent, a survey by The Vegetarian Resource Group confirms the above. Of 267 vegans and vegetarians surveyed in 2006, 153 responded again in 2009; 91 percent and 94 percent of health and ethical, meaning cruelty-free, vegetarians, respectively, indicating that they had remained vegetarian/vegan, while 100 percent of 
environmental vegetarians did so (Vegetarian Resource Group, 2009).

Yet data compared from survey to survey raises inconsistencies. A 2011 Psychology Today survey of seventy-seven former vegetarians cited animal welfare as the chief motivator for going meatless, at fifty-seven percent, with health and environmental reasons cited by only 15 percent - a stark contrast to the Vegetarian Times survey (Herzog, 2011). While respondents gave a variety of reasons for returning to a meat-based diet, significantly, moral convictions remained strong, as only two respondents indicated that a change in their moral views concerning animal welfare played a factor in consuming meat again.

\section{GATEWAYS}

While further research is needed, online evidence suggests that animal welfare is the most common motivator for adopting a meatless diet. It is a powerful emotional influence that lends itself to forceful visual metaphors with some evidence that it reinforces conviction and commitment to go meatless. Much could be accomplished toward developing advocacy for a more sustainable food system by more closely connecting animal rights advocacy to the global food system, both environmentally and in terms of social justice. The danger is an argumentative line that relies on, e.g., charismatic mega-fauna or adorable kittens. The former is often too far removed from local needs and emotional connections to bring audiences on board while the latter can be an emotional distraction that loses the forest for the trees; both can seem alternately frivolous and callous in light of social justice concerns if not connected to the larger system.

Health-related arguments for going meatless are more complex but potentially more accessible to audiences than arguments regarding climate and/or sustainable food systems-as they are personal. Persuasive techniques focusing on personal health may also be seen by many audiences as less politically charged and/or less radical. Unfortunately, Keys' study may not serve as the best foundation for such arguments, as his findings have come under question. Indeed, even as Key's ideas were taking hold in the health community during the 1970s, a number of studies pointed toward sugar, rather than fat, as the offender in heart disease, but the findings were never brought to the public's attention. Recent studies again point toward sugar, for among other things, the livers of rats fed levels of sugar common in the U.S. diet metabolized the sugar into palmitate, the fat that raises LDL cholesterol, which has been linked to heart disease (Taubes, 2011; Peretti, 2012). Thus, 
health strategies may gain more traction in the future by focusing on weight loss, antibiotics and hormones in the meat supply, and food-borne pathogens, such as $E$ coli.

Ultimately, the best strategy for persuading audiences to reduce or abstain from animal protein consumption seems to be a combined strategy -as the rationales intersect. For example, health can be linked to animal rights as CAFOs are not only cruel to livestock but also create conditions for the outbreak of food-borne pathogens such as e-coli. Singer's work provides a starting place for animal rights concerns, as evidence mounts that confinement feeding drastically limits animal movement and leads to a variety of stresses and illnesses among livestock. Moreover, Singer's position that one may be a "conscientious omnivore" may provide a bridge to individuals resistant to vegetarianism, encouraging them to reduce their consumption of meat or to restrict their consumption to livestock raised in cruelty-free and sustainable conditions.

Meanwhile, as noted by Lappé, reducing consumption of animal protein is the most effective way to reduce one's environmental impact. On average, animal protein production requires 28 kilocalories of energy to produce one calorie of animal protein compared to 3.3 calories to produce one kilocalorie of grain protein (Pimentel, 1997). More than half of U.S. grain and 40 percent of global grain goes to feed livestock. Globally, increased grain production has reduced acreage planted in highly nutritious fruits, vegetables, and greens, depleted soil quality and quantity, polluted air and water, consumed vast amounts of water, and contributed megatons of greenhouse gasses to the atmosphere. Moreover, conventional farming methods compete with traditional farming methods that sustain local economies, food access, and foodways (Jorgensen, 2012).

Indeed, many of the web sites under study do employ a multipronged strategy, although some do so in much more depth than others. Rhetorical strategists with concern about food systems would do well to encourage vegetarian organizations, health organizations, and animal welfare organizations to contextualize their concerns to the bigger picture as well as to encourage early and frequent adoption of food systems curricula in the nation's schools. In sum, persuading the public to adopt more sustainable dietary practices requires a complex approach, as the food system cannot be extracted from energy, waste, and water systems nor can any of these be extracted from the natural systems of climate and habitat. 


\section{REFERENCE LIST}

Aubrun, A., A. Brown, and J. Grady. "Not While I'm Eating: How and Why Americans Don't Think About Food Systems: Findings from the TalkBack Testing." 2005. Frameworks Institute. <http://frameworksinstitute.org/toolkits/foodsystem/docs/f oodsyselic.pdf $>$. Accessed 22 May 2009.

Bluejay, M. Vegetarian Guide-Recipes, Cookbooks, Articles and More. N.d. <http://michaelbluejay.com/veg/> . Accessed 8 February 2014.

Bostrom, M. "Digesting Public Opinion: A Meta-Analysis of Attitudes toward Food, Health and Farms." 2005. Frameworks Institute. $<$ http://frameworksinstitute.org/assets/files/PDF_FoodSyst ems/food_systems_meta_analysis.pdf $>$. Accessed 21 February 2014.

Brundtland, G.H. Report of the World Commission on Environment and Development: "Our Common Future." 1987. United Nations World Commission on Environment and Development. $<$ http://conspect.nl/pdf/Our_Common_FutureBrundtland_Report_1987.pdf $>$. Accessed 23 February 2014.

Caton, G.J. “50 Reasons Why I'm a Vegetarian.” N.d. Lumen Foods: 50 Reasons. <http://www.gregcaton.com/lumen/5orea.htm>. Accessed 8 February 2014.

Center for Food Integrity. "Consumer Trust Research 2013: Seven Steps to Trust-Building Transparency and Defining Social Outrage." 2013. The Center for Food Integrity: 2013 Research. <http://www.foodintegrity.org/research>. Accessed 2 March 2014.

ChooseVeg. N.d. <http://www.chooseveg.com/?locale=en-US>. Accessed 8 February 2014.

Euromonitor International. "The War on Meat: How Low-Meat and No-Meat Diets are Impacting Consumer Markets." 2011. The War on Meat: How Low-Meat and No-Meat Diets are Impacting Consumer Markets | Analyst Insight from Euromonitor International. $<$ http://blog.euromonitor.com/2011/o8/the-war-on-meathow-low-meat-and-no-meat-diets-are-impacting-consumermarkets.html>. Accessed 2 March 2014. 
Friedrich, B. and C. Akin. Meet Your Meat. 2002. Meet Your Meat | Videos | PETA. <http://www.peta.org/videos/meet-yourmeat/>. Accessed 20 March 2014.

Happy Cow: The Healthy Eating Guide. "Compassion for the Animals.” N.d. Animal Rights and Vegetarianism-Why Be a Vegetarian?

<http://www.happycow.net/why_vegetarian.html>. Accessed 8 February 2014.

GoVeg. N.d. Home | goveg. <http://goveg.kiwi.nz/>. Accessed 8 February 2014.

Hackett, J. “Readers Respond: Why Are You Vegetarian?” 2014. About.com. $<$ http://vegetarian.about.com/u/ua/vegetarianvegan101/veg etarianreasons.htm>. Accessed 12 February 2014.

Harris Interactive Polling. "Vegetarianism in America." 2008. Vegetarian Times. $<$ http://www.vegetariantimes.com/article/vegetarianism-inamerica/>. Accessed 8 February 2014.

Herzog, H. "Why Do Most Vegetarians Go Back to Eating Meat?" 2011. Psychology Today. $<$ http://www.psychologytoday.com/blog/animals-andus/201106/why-do-most-vegetarians-go-back-eating-meat>. Accessed 8 February 2014.

Jensen, T. “Food Issues Polarizing America.” 2013. Public Policy Polling. <http://www.publicpolicypolling.com/main/2013/o2/foodissues-polarizing-america.html> . Accessed 28 February 2013.

Jorgensen, B. "Give Us This Day: The Grain Meme in Environmental and Food Justice Discourse." 2012 International Professional Communication Conference (IPCC) Proceedings (2012): 1,14, 8-10. $<$ http://ieeexplore.ieee.org/xpl/articleDetails.jsp?arnumber= 6408599>. Accessed 23 March 2014.

Keys, A., A. Menotti, C. Aravanis, H. Blackburn, B.S. Djordevič, R. Buzina, A.S. Dontas, F. Fidanza, M.J. Karvonen, N. Kimura, I. Mohaek, S. Nedeljkovič, V. Puddu, S. Punsar, H.L. Taylor, S. Conti, D. Kromhout, and H. Toshima. Seven Countries: A Multivariate Study of Death and Coronary Heart Disease. Cambridge: Harvard University Press, 1980. 
Lappé, F.M. Diet for a Small Planet: How to Enjoy a Rich Harvest by Getting off the Top of the Food Chain. New York:

Ballantine Books, Inc., 1971.

Munkres, S. "Exploring Consumer Perceptions in a Food Backwater." 2007. Consumption.

$<$ http://csrn.camden.rutgers.edu/newsletters/9-

1/munkres.htm>. Accessed 22 May 2009.

Newport, F. "Five Percent of American Adults Consider Themselves To Be Vegetarians." 2012. Gallup Well-being. $<$ http://www.gallup.com/poll/156215/consider-themselvesvegetarians.aspx>. Accessed 24 February 2014.

North American Vegetarian Society. N.d. <https://www.navsonline.org/>. Accessed 8 February 2014.

Peretti, J. "Why Our Food is Making Us Fat." 2012. The Guardian. <http://www.guardian.co.uk/business/2012/jun/11/whyour-food-is-making-us-fat>. Accessed 19 February 2014.

People for the Ethical Treatment of Animals. "Top Ten Reasons to Go Vegan in the New Year." N.d. Top Ten Reasons to Go Vegan in the New Year | Vegan Food | Living | PETA. $<$ http://www.peta.org/living/food/top-10-reasons-go-vegannew-year/> . Accessed 8 February 2014.

Pimentel, D. "Livestock Production: Energy Inputs and the Environment.” In Scott, S.L. and X. Zhao (Eds.) Proceedings of the Canadian Society of Animal Science (Pp. 17-26). Montreal: Canadian Society of Animal Science, 1997.

Pirog, R. and R. Rasmussen. "Food, Fuel and the Future: Consumer Perceptions of Local Food, Food Safety and Climate Change in the Context of Rising Prices." 2008. Leopold Center for Sustainable Agriculture.

$<$ http://www.leopold.iastate.edu/pubs/staff/consumer2/con sumer2.pdf $>$. Accessed 22 May 2009.

Priestley, J. An Essay on the First Principles of Government. London: J. Johnson, 1768.

Singer, P. Animal Liberation: A New Ethics for Our Treatment of Animals. New York: Random House, 1975. Rpt. 2009.

Taubes, G. “Is Sugar Toxic?” 2011. New York Times Sunday Magazine.

<http://www.nytimes.com/2011/04/17/magazine/mag17Sugar-t.html?pagewanted=all\&_r=0 $>$. Accessed 19 February 2014. 
TryVeg. N.d. <http://tryveg.com/>. Accessed 8 February 2014.

Vegetarian Food Online Store. "Ten Reasons to Be a Vegetarian."

N.d. Vegecyber. <http://www.vegecyber.com/cgibin/vege_item.cgi?html=../others/about_vegetarianism.sht ml>. Accessed 22 February 2014.

Vegan Outreach. N.d.

<http://www.veganoutreach.org/VO_Trifold.pdf $>$. Accessed 8 February 2014.

The Vegetarian Resource Group. "Do Vegetarians and Vegans Stay Vegetarian?” 2009. Vegetarian Resource Group | Retention Survey-2009.

<http://www.vrg.org/research/retention_survey_2009.php > . Accessed 8 February 2014.

The Vegan Society. "Why Go Vegan?” N.d. Why Go Vegan | The Vegan Society. <http://www.vegansociety.com/tryvegan/why-go-vegan>. Accessed 8 February 2014.

The Vegetarian Resource Group. "Vegetarianism in a Nutshell." 2000. Poll on Vegetarianism in the U.S. <http://www.vrg.org/nutshell/poll20oo.htm>. Accessed 8 February 2014.

Vegetarian Victoria. “Why Be Vegetarian?” N.d. Why Be Vegetarian | Vegetarian Victoria. $<$ http://www.vegetarianvictoria.org.au/goingvegetarian/why-be-vegetarian-.html $>$. Accessed 8 February 2014.

The Vegetarian Site. 2014. <http://www.thevegetariansite.com/index.htm>. Accessed 8 February 2014.

Vegetarian Times. "Why Go Veg?” N.d. Why Go Vegetarian or Vegan | Vegetarian Times. <http://www.vegetariantimes.com/article/why-go-veg-learnabout-becoming-a-vegetarian/>. Accessed 8 February 2014.

VeggieGlobal. N.d. < http://www.veggieglobal.com/menu.htm>. Accessed 8 February 2014.

VegNews. N.d. <http://vegnews.com/> Accessed 8 February 2014.

VegSource. 2014. <http://www.vegsource.com/>. Accessed 8 February 2014.

Watson, A. "Illustrated History of Heart Disease 1825-2015." 2013. Illustrated History of Heart Disease 1825-2015 | Diet Heart 
Publishing. <http://www.dietheartpublishing.com/dietheart-timeline >. Accessed 1 October 2014.

Why Be Vegetarian. "Why Be a Vegetarian?" N.d. Why Be

Vegetarian. <http://whybevegetarian.net/>. Accessed 8 February 2014. 